\title{
SAINTEKS: JURNAL SAIN DAN TEKNIK
}

\author{
Volume 1, Nomor 2 Tahun 2019
}

E-ISSN: 2685-8304

Sistem Pengolahan Air Limbah Elektroplating Berbasis Nikel Djaenudin, Galu Murdikaningrum, Kenny Kencanawati, Wendi Hermawan $57-68$

Perbandingan Model Characteristic Drying Rate Curve dan Reaction Engineering Approach Berdasarkan Hasil Eksperimen Pengeringan Mango Tissues Johannes Martua Hutagalung

69-76

Penentuan Jumlah Pesanan Bahan Baku Pada Sistem Persediaan Backorder Di PT ABC Tombak Gapura Bhagya $77-87$

Studi Tentang Program Operasi Danau Jatiluhur Jernih untuk Mendukung Revitalisasi Waduk Jatiluhur Riza Rizkiah $87-98$

Pengaruh Taut Silang Natrium Tripolifosfat Dengan Kitosan Terhadap Sifat Fisis Chitosan Edible Film Sebagai Drug Delivery System Mutiara Putri Utami Susanto

98-103

Analisis Faktor-Faktor Penerimaan Konsumen Pada Aplikasi E-Marketplace Lazada Menggunakan TAM

Graha Prakarsa 103-115

Diterbitkan Oleh: UNIVERSITAS BANDUNG RAYA dpm. UNIVERSITAS INSAN CENDEKIA MANDIRI

Fakultas Teknik JI . Banten 11 Bandung, Jawa Barat http :// sainteks.uicm-unbar.ac..id






\title{
Analisis Faktor-faktor Penerimaan Konsumen Pada Aplikasi E-Marketplace Lazada Menggunakan TAM
}

\author{
Graha Prakarsa \\ Program Studi Sistem Informasi Universitas Informatika dan Bisnis Indonesia \\ Email: gprakarsa@gmail.com
}

\begin{abstract}
The increasing number of buying and selling transactions through e-marketplaces today causes the need for a model that is able to measure the extent of acceptance of e-marketplace applications. The existence of a model of measuring e-marketplace acceptance will greatly help business people in that field in order to improve the performance of the service products it offers, which in this study is Lazada. This research was conducted to find out how far the user acceptance of Lazada e-marketplace applications using the Technology Acceptance Model (TAM). The approach on this research is using quantitative approach with a survey method. Data collection techniques were carried out using questionnaires that were randomly distributed to Lazada e-marketplace users. The data analysis method used is descriptive analysis using multiple linear regression data analysis techniques. The results showed that content richness, security and perceived ease of use variables had a significant effect on the perceived of usefulness variable, security variables had a significant effect on perceived usefulness variables, perceived usefulness variables, perceived ease of use and security had a significant effect on the variables customers intention to use.
\end{abstract}

Keywords: TAM, e-marketplace, lazada

\begin{abstract}
Abstrak: Semakin banyaknya proses transaksi jual beli melalui e-marketplace saat ini menyebabkan perlunya suatu model yang mampu mengukur sejauh mana tingkat penerimaan aplikasi e-marketplace. Adanya suatu model pengukuran penerimaan e-marketplace akan sangat membantu para pelaku bisnis di bidang tersebut agar dapat meningkatkan kinerja produk jasa yang ditawarkannya, yang dalam penelitian ini yaitu Lazada. Penelitian ini dilakukan untuk mengetahui seberapa jauh penerimaan pengguna aplikasi e-marketplace Lazada berdasarkan Technology Acceptance Model (TAM). Pendekatan penelitian ini menggunakan pendekatan kuantitatif dengan metode survey. Teknik pengumpulan data dilakukan dengan menggunakan angket yang disebar secara random kepada pengguna e-marketplace Lazada. Metode analisis data yang digunakan yaitu analisis deskriptif menggunakan teknik analisis data regresi linear berganda. Hasil penelitian menunjukkan bahwa variabel content richness, security dan perceived ease of use berpengaruh signifikan terhadap variabel perceived of usefulness, variabel security berpengaruh signifikan terhadap variabel perceived usefulness, variabel perceived usefulness, perceived ease of use dan security berpengaruh signifikan terhadap variabel customers intention to use.
\end{abstract}

Kata Kunci: TAM, e-marketplace, lazada

\section{PENDAHULUAN}

Perkembangan teknologi yang semakin pesat, membuat kegiatan manusia semakin mudah. Salah satunya dalam kegiatan berbelanja. Kini komunikasi untuk berbelanja sudah banyak dilakukan secara. Karena kini orang lebih cenderung suka dengan segala sesuatu yang praktis, cepat, mudah dan murah.

Suatu e-marketplace agar mendapatkan banyak pengguna maka ia harus memenuhi salah satu syarat wajib, yaitu memperhatikan faktor kemudahan dalam penggunaan. Apabila konsumen merasakan kesulitan dalam melakukan kegiatan transaksi pada suatu suatu emarketplace maka sudah barang tentu ia tidak akan menggunakannya. Sekompetitif apapun harga yang ditawarkan pada situs tersebut, akan tetapi bila konsumen merasa kesulitan untuk melakukan proses transaksi, maka hal tersebut akan sia-sia. Alasan "Kemudahan untuk bertransaksi" merupakan alasan paling utama dari hasil penelitian Nielsen (1999) dengan besaran angka 83\% dari seluruh responden, mengenai kemauan seseorang untuk melakukan transaksi online. Menurut Lai dan Li (2011) menyatakan bahwa kepercayaan para pelanggan terhadap proses transaksi di internet juga perlu diperhatikan. Artiya dalam suatu bisnis online, 
kita selayaknya menjaga privacy serta keamanan selama proses transaksi berlangsung. Dengan demikian, kepercayaan merupakan faktor yang cukup penting dalam suatu proses transasi di internet (Lai and Li, 2011). Selanjutnya Gefen and Straub (2003) mengemukakan bahwa faktor kepercayaan ini telah terbukti akan meningkatkan penggunaan melalui timbulnya karena akan mengurangi rasa ketidakpastian dalam penggunaan.

Salah satu cara mengukur penerimaan terhadap teknologi adalah melalui model penerimaan teknologi (TAM). Model TAM mengungkapkan bahwa para pengguna suatu sistem akan cenderung mau menggunakan sistem apabila sistem yang dia gunakan dirasakan mudah dan bermanfaat baginya. Konsep atau model TAM sendiri dilandasi oleh Theory of Reasoned Action (TRA) atau teori tindakan beralasan yang dikembangkan oleh Fishbein dan Ajzen (1975). Dalam TAM, perceived usefulness dan perceived ease of use merupakan 2 faktor kunci yang mempengaruhi penerimaan pemakai suatu sistem informasi. Davis (1989) mengembangkan konsep TAM untuk menawarkan sebuah teori yang dapat dijadikan landasan mempelajari dan memahami perilaku pemakai dalam menerima dan menggunakan sebuah teknologi/sistem informasi. Dengan demikian, penelitian terkait dengan perluasan terhadap konsep TAM diharapkan akan membantu untuk lebih jauh memprediksi sikap dan penerimaan seseorang terhadap teknologi yang digunakannya serta dapat memberikan informasi mendasar yang diperlukan mengenai faktor-faktor apa saja yang bisa menjadi pendorong sikap pengguna tersebut (Lee and Panteli, 2010).

Terdapat banyak penelitian yang dilakukan terhadap variabel penelitian dari model pengembangan TAM. Salah satunya yang dilakukan Venkates dan Davis (2000) yang menggagaskan mengenai pengukuran kesuksesan sebuah sistem dapat dilakukan melalui beberapa variabel yaitu perceived usefulness serta perceived ease of use. Bahwa perceived usefulness merupakan tingkat kepercayaan seseorang bila seseorang tersebut menggunakan suatu sistem akan meningkatkan kinerjanya. Perceived ease of use merupakan tingkatan seseorang yang percaya bahwa dengan menggunakan suatu sistem maka akan mempermudahnya dalam proses penyelesaian pekerjaannya (Venkates dan Davis, 2000)

Lazada sebagai salah satu e-marketplace yang menyediakan berbagai jenis produk, mulai dari perlengkapan elektronik hingga peralatan rumah tangga. Lazada adalah salah satu situs emarketplace ber-tipe B2C (business to customer) merupakan salah satu ranking yang tinggi di Indonesia. Berdasarkan Alexa (www.alexa.com), Lazada menempati ranking 15 di Indonesia yang mana merupakan tertinggi untuk situs belanja. Lazada juga merupakan 10 e-marketplace dengan pengunjung terbanyak di Indonesia yaitu sebanyak 117,6 Juta pengguna. Dengan ratusan ribu pilihan produk dari brand internasional dan lokal yang tersedia di Lazada, tentunya Lazada menjadi tujuan bagi banyak orang untuk memenuhi kebutuhanya.

Penelitian ini merupakan pengembangan dari penelitian yang dilakukan Venkatesh \& Davis (1996). Pada penelitian Venkatesh \& Davis (1996), model yang dikembangkan masih dibuat sebagai model umum penerimaan teknologi informasi, artinya tidak dibuat secara khusus mengukur teknologi informasi berbasis mobile ataupun aplikasi. Artinya model sebelumnya belum tentu dapat mewakili faktor-faktor teknologi informasi yang dibutuhkan, dalam hal ini penerimaan e-marketplace. Perbedaan yang ada pada penelitian ini dibandingkan penelitian Venkatesh \& Davis (1996) yaitu penjabaran pada variabel eksternal serta penyederhanaan model dengan meniadakan variabel usage behavior. Perubahan tersebut dilakukan dalam rangka mencocokkan model penelitian dengan kasus pada penelitian ini yang berfokus pada penerimaan e-marketplace. Dengan demikian penelitian ini memperkaya model pada penelitian sebelumnya yang berguna secara spesifik untuk mengukur penerimaan $e$-marketplace.

\section{METODE}

Metode survai merupakan metode yang digunakan pada penelitian ini. Adapun metode survei sendiri merupakan suatu metode yang mempelajari data berdasarkan suatu sampel untuk mengukur hubungan antar variabel pada suatu populasi (Sugiyono, 2015). Menurut Singarimbun (1995), suatu penelitian yang mengambil sejumlah sampel dari populasi melaui 
kuesioner untuk mengumpulkan data pokok termasuk ke dalam kategori penelitian survei. Jika diuraikan penelitian ini mengadopsi kerangka pemikiran yang telah di modifikasi oleh Pindeh et al. (2015), Lai (2016), dan Prakarsa (2019) dengan menggunakan 3 variabel utama dan 2 variabel eksternal. Variabel utama yang digunakan yaitu: perceived usefulness, perceived ease of use dan Consumers Intention To use. Adapun variabel eksternalnya yaitu content richness (kekayaan konten) dan security (keamanan).

\section{- Content Richness (CR)}

Content richness atau kekayaan konten didefinisikan sebagai suatu sumber daya yang bisa diakses oleh pengguna agar terjadi peningkatan aktivitas penggunaan teknologi tertentu sehingga akan mempengaruhi variabel perceived usefulness (Prakarsa, 2019). Pengukuran item dari Content richness melibatkan tiga dimensi yaitu: relevansi, ketepatan waktu, dan kecukupan (Pindeh et al., 2016).

\section{- Security (S)}

Keamanan didefinisikan sebagai keadaan terlindung atau aman dari bahaya. Keamanan dalam penelitian ini meliputi trust (kepercayaan) dan risk (resiko) (Luthfihadi dan Dhewanto, 2013). Keamanan biasanya dikaitkan dengan organisasi yang menyediakan tingkat keamanan untuk konsumen dan resiko biasanya dikaitkan dengan kepercayaan konsumen dalam mengadopsi teknologi baru. Adapun definisi dari Trust (kepercayaan) menurut Gefen et al. (2003) dalam Luthfihadi \& Dhewanto (2013) yaitu: "a belief that promises are reliable and obligations will be fulfilled". Kepercayaan adalah aspek paling krusial dalam suatu transaksi, terutama dalam transaksi yang bersifat online. Ukuran serta reputasi dari vendor transasksi online merupakan beberapa faktor yang akan mempengaruhi kepercayaan pada online store (Jarvenpaa dalam Loanata \& Tileng, 2016) dan Prakarsa (2019). Dengan demikian reputasi suatu vendor online ini dianggap salah satu faktor yang mempengaruhi tingkat kepercayaan pada toko online pada penelitian ini.

Definisi resiko memiliki beberapa makna. Resiko bagi konsumen dalam transaksi $e$ commerce lebih besar dibandingkan transaksi secara konvensional/fisik. (Luthfihadi \& Dhewanto, 2013). Terkait konteks e-commerce, definisi resiko adalah ketidakpastian yang dirasakan oleh konsumen secara khusus (situasi pembelian) (Gefen et al., 2003). Faktor keamanan telah banyak ditemukan pada penelitian-penelitian terdahulu sebagai sebuah prediktor yang signifikan terhadap pengadopsian e-commerce (Prakarsa, 2019). Pengukuran item dari Security melibatkan tiga dimensi yaitu: integritas penjual, reputasi dan kejujuran (Gefen et al., 2003).

\section{- Perceived Ease of Use (PEOU)}

Davis (1986) mengemukakan bahwa perceived ease of use merupakan: "the degree to which a person believes that using a particular system would be free of physical and mental efforts". Dengan demikian faktor tersebut menjelaskan mengenai sejauh mana seseorang akan percaya bahwa menggunakan dengan suatu teknologi atau sistem tertentu akan terbebas dari usaha fisik maupun mental (usaha) seseorang saat mengerjakan sesuatu. Kemudahan (ease) tersebut mengandung makna usaha yang dilakukan tanpa kesulitan atau tanpa perlu usaha yang keras. Persepsi kemudahan (perceived ease of use) ini melihat pada keyakinan pengguna bahwa sistem atau teknologi yang digunakannya tidak memerlukan suatu usaha yang besar saat penggunaannya. Dengan demikian variabel perceived ease of use ini akan mempengaruhi customer intention to use secara signifikan (Prakarsa, 2019).

Pengukuran item dari perceived ease of use melibatkan 6 faktor, yaitu: Kemudahan untuk dipelajari, Dapat dikontrol, Jelas dan mudah dipahami, Fleksibel, Mudah untuk menjadi terampil dan Kemudahan penggunaan (Davis, 1989).

\section{- Perceived Usefulness (PU)}

Menurut Davis Persepsi kegunaan (perceived usefulness) didefinisikan sebagai: "the degree to which a person believes that using particular system would enhance his or her job performance" (Davis, 1989:320). Persepsi kegunaan (perceived usefulness) artinya hal ini memperhatikan 
mengenai sejauh mana seseorang akan percaya bahwa dengan suatu sistem tertentu akan dapat meningkatkan prestasi kerja atau kinerja pengguna sistem tersebut. Variabel perceived usefulness ini akan mempengaruhi customer intention to use secara signifikan (Prakarsa, 2019).

Pengukuran item dari perceived usefulness melibatkan 6 dimensi yaitu: Mempercepat pekerjaan, Meningkatkan kinerja, Meningkatkan produktifitas, Mempertinggi efektivitas, Mempermudah pekerjaan dan Berguna/bermanfaat (Davis, 1989).

\section{- Consumers Intention to use (CITU)}

Consumers Intention to use atau disebut juga niat perilaku untuk menggunakan (behavioral intention to use) yaitu suatu tingkatan di mana seseorang secara sadar melakukan atau tidak melakukan suatu perilaku di waktu yang akan datang di mana telah ditentukan sebelumnya (Davis et al., 1989). Pengukuran item dari Consumers Intention to use melibatkan 6 dimensi yaitu: Minat menggunakan, Niat meningkatkan penggunaan, Memotivasi pengguna lain, Konsisten, Keinginan menggunakan pada waktu tertentu dan Prioritas penggunaan (Davis, 1989).

Berdasarkan penjelasan di atas, maka di dapatkan hubungan dan pengaruh dari setiap variabel sebagaimana gambar berikut ini:

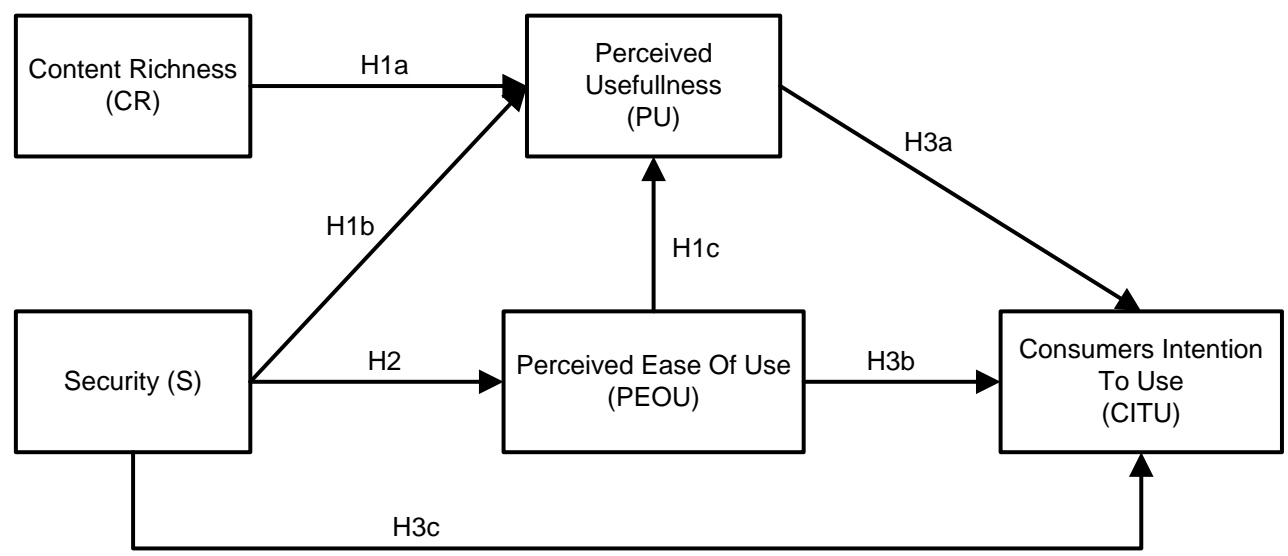

Gambar 1 Model Penelitian

Gambar 1 di atas secara langsung juga menunjukkan hipotesis pada penelitian ini yang dikemukakan sebagai berikut:

1) Ada pengaruh yang signifikan antara Content Richness, Security dan Perceived Ease of Use terhadap Perceived Usefulness pada aplikasi e-marketplace Lazada.

2) Ada pengaruh yang signifikan antara Security terhadap Perceived Ease of Use pada aplikasi emarketplace Lazada.

3) Ada pengaruh yang signifikan antara Security, Perceived Ease of Use, dan Perceived Usefulness terhadap Consumers Intention to Use pada aplikasi e-marketplace Lazada.

Seluruh pengguna e-marketplace yang sudah pernah melakukan suatu kegiatan transaksional secara online minimal 1 kali di situs/aplikasi e-marketplace Lazada merupakan populasi pada penelitian ini. Penentuan sampel dalam penelitian ini melalui banyaknya jumlah variabel yang kemudian dikalikan 10 (Ruscoe dalam Sugiyono, 2015). Dengan demikian, pada penelitian ini jumlah jumlah responden minimal yang dijadikan sampel sebanyak 50 orang karena variabel yang diteliti sebanyak 5 .

Penelitian ini menggunakan beberapa teknik pengumpulan data, antara lain: (1) Angket; merupakan penyebaran pertanyaan yang bersifat tertutup kepada responden penelitian. (2) Observasi, merupakan teknik pengumpulan data dengan cara melakukan pengamatan terhadap obyek penelitian. Instrument atau angket pada penelitian diuji baik validitasnya maupun reliabilitanya. Teknik analisis data yang digunakan pada penelitian ini yaitu analisis data regresi, yang ditujukan untuk menguji model dan hipotesis yang dikembangkan. 


\section{HASIL PENELITIAN DAN PEMBAHASAN}

Hasil pengujian validitas dan reliabilitas pada penelitian ini menunjukkan bahwa setiap angket telah telah valid dan reliabel dengan nilai yang baik. Hal tersebut ditunjukkan dengan nilai $r$ atau nilai korelasi dari setiap skors item dengan totalnya telah menunjukkan nilai koefisien signifikan serta mempunyai nilai reliabilitas yang reliabel.

Pengujian validitas pada penelitian ini dilihat berdasarkan nilai koefisien korelasi setiap item pernyataan dengan total item lainnya dan menunjukkan nilai lebih besar dari nilai $r$ tabel $=$ 0,266. Dengan demikian hasil uji validitas ini menunjukkan bahwa semua item pernyataan yang di ajukan pada kelima variabel penelitian ini adalah telah valid serta telah sudah layak untuk disebarkan dan digunakan sebagai alat ukur pada suatu penelitian. Hasil pengujian reliabilitas pada penelitian ini didasarkan pada nilai alpha atau $\mathrm{r} 11>\mathrm{r}$ tabel maka istrumen tersebut dikatakan reliabel. Hasilnya pengujiannya menunjukkan nilai yang baik untuk variabel content richness, security, perceived ease of use, perceived usefulness, consumers intention to use, telah memberikan nilai Cronbach's Alpha $(\alpha)$ masing-masing $>0,60$. Dengan demikian dapat disimpulkan bahwa instrument penelitian ini atau kuesioner telah reliabel.

\section{1) Pengujian Hipotesis 1}

Pengujian hipotesis 1 dilakukan untuk melihat bagaimana pengaruh variabel Content Richness, Security dan Perceived Easy of Use terhadap Perceived Usefullness. Pengujian hipotesis ini meliputi pengujian heterokedastisitas, pengujian koefisien determinasi, analisis regresi berganda serta pengujian $\mathrm{F}$.

Pada penelitian ini pegujian heteroskedastisitas menggunakan metode uji Glejser, dengan ketentuan yaitu jika nilai signifikansi $>0,05$ maka tidak terjadi heteroskedastisitas, sebaliknya jika nilai signifikansi $<0,05$ maka terjadi heteroskedastisitas.

Tabel 1 Hasil Uji Heteroskedastisitas Hipotesis 1

\begin{tabular}{|c|c|c|c|c|c|c|}
\hline \multicolumn{7}{|c|}{ Coefficients $^{a}$} \\
\hline \multirow{2}{*}{\multicolumn{2}{|c|}{ Model }} & \multicolumn{2}{|c|}{ Unstandardized Coefficients } & \multirow{2}{*}{$\begin{array}{c}\text { Standardized } \\
\text { Coefficients }\end{array}$} & \multirow[t]{2}{*}{$t$} & \multirow[t]{2}{*}{ Sig. } \\
\hline & & $\mathrm{B}$ & Std. Error & & & \\
\hline \multirow[t]{4}{*}{1} & (Constant) & 4.088 & 3.375 & & 1.211 & .231 \\
\hline & $\mathrm{CR}$ & -.104 & .108 & -.132 & -.956 & .344 \\
\hline & $\mathrm{S}$ & .135 & .138 & .202 & .981 & .331 \\
\hline & PEOU & -.134 & .104 & -.264 & -1.288 & .204 \\
\hline
\end{tabular}

Sumber: Data primer diolah (2019).

Berdasarkan tabel hasil uji heteroskedastisitas Glejser di atas diperoleh hasil berikut. Variabel Content Richness (CR), Security (S) dan Perceived Ease Of Use (PEOU) menghasilkan nilai masing-masing sig. $>0,05$. Dengan demikian dapat disimpulkan bahwa seluruh variabel $\mathrm{H} 1$ telah terbebas dari masalah heteroskedastisitas.

Koefisien determinasi digunakan untuk mengukur kesesuaian regresi berganda terhadap suatu data. Apabila semakin tinggi Adjusted R maka semakin baik pula suatu model regresi, ini berarti variabel bebas semakin mampu menjelaskan variabel terikat.

Tabel 2 Hasil Uji Koefisien Determinasi Hipotesis 1

\begin{tabular}{|l|c|c|c|c|}
\hline \multicolumn{6}{|c|}{ Model Summary $^{\mathbf{b}}$} \\
\hline Model & $\mathrm{R}$ & R Square & Adjusted R Square & $\begin{array}{c}\text { Std. Error of the } \\
\text { Estimate }\end{array}$ \\
\hline 1 & $.421^{\mathrm{a}}$ & .177 & .129 & 2.121 \\
\hline \multicolumn{2}{|c|}{ a. Predictors: (Constant), PEOU, CR, S } \\
\hline \multicolumn{2}{|l|}{ b. Dependent Variabel: PU }
\end{tabular}

Sumber: Data primer diolah (2019) 
Nilai adjusted $\mathrm{R}^{2}$ 0,129 berarti daya penjelas variabel independen: Content Richness (CR), Security (S) dan Perceived Easy Of Use (PEOU) terhadap variabel dependen: Perceived Usefullness (PU) adalah sebesar 12,9\%, sedangkan sisanya dijelaskan oleh faktor-faktor lain di luar model.

Analisis regresi linear berganda digunakan untuk melihat apakah variabel independen secara simultan memiliki pengaruh terhadap variabel dependen.

Tabel 3 Hasil Analisis Regresi Berganda Hipotesis 1 Coefficients $^{\mathbf{a}}$

\begin{tabular}{|c|c|c|c|c|c|c|}
\hline \multicolumn{7}{|c|}{ Coefficients $^{\mathbf{a}}$} \\
\hline \multirow{2}{*}{\multicolumn{2}{|c|}{ Model }} & \multicolumn{2}{|c|}{ Unstandardized Coefficients } & \multirow{2}{*}{$\begin{array}{c}\begin{array}{c}\text { Standardized } \\
\text { Coefficients }\end{array} \\
\text { Beta }\end{array}$} & \multirow[t]{2}{*}{$\mathrm{t}$} & \multirow[t]{2}{*}{ Sig. } \\
\hline & & B & Std. Error & & & \\
\hline \multirow[t]{4}{*}{1} & (Constant) & 16.423 & 4.853 & & 3.384 & .001 \\
\hline & $\mathrm{CR}$ & .151 & .156 & .125 & .970 & .337 \\
\hline & $\mathrm{S}$ & -.292 & .198 & -.282 & -1.471 & .148 \\
\hline & PEOU & .439 & .150 & .558 & 2.932 & .005 \\
\hline
\end{tabular}

Sumber: Data primer diolah (2019) .

Berdasarkan tabel di atas dapat dituliskan ke dalam persamaan sebagai berikut:

$$
\begin{gathered}
\widehat{Y}=b 0+b 1 X 1+b 2 X 2+\cdots+b k x k \\
Y=16,423+0,151 X 1-0,292 X 2+0,493 X 3
\end{gathered}
$$

Kesimpulan persamaan regresi di atas yaitu sebagai berikut:

1. Konstanta $\left(b_{0}\right)$ sebesar 16,423 , ini mengartikan bahwa nilai konstanta variabel Perceived Usefullness adalah sebesar16,423.

2. Koefisien regresi Content Richness (CR) sebesar 0,151, menyatakan bahwa setiap penambahan 1 nilai Content Richness (CR), maka nilai Perceived Usefullness (PU) bertambah sebesar 0,151. Koefisien regresi tersebut bernilai positif, sehingga dapat dikatakan bahwa arah pengaruh variabel Content Richness (CR) terhadap variabel Perceived Usefullness (PU) adalah positif.

3. Koefisien regresi Perceived Ease of Use (PEOU) sebesar 0,439, menyatakan bahwa setiap penambahan 1 nilai Perceived Ease of Use (PEOU), maka nilai Perceived Usefullness (PU) bertambah sebesar 0,439. Koefisien regresi tersebut bernilai positif, sehingga dapat dikatakan bahwa arah pengaruh variabel Perceived Ease of Use (PEOU) terhadap variabel Perceived Usefullness (PU) adalah positif.

4. Koefisien regresi Security (S) sebesar -0,292, menyatakan bahwa setiap penambahan 1 nilai Security (S), maka nilai Perceived Usefullness (PU) berkurang sebesar 0,292. Koefisien regresi tersebut bernilai negatif, sehingga dapat dikatakan bahwa arah pengaruh variabel Security (S) terhadap variabel Perceived Usefullness (PU) adalah negatif.

Uji $\mathrm{F}$ digunakan untuk melihat hubungan antara satu variabel dependen dengan satu atau lebih variabel independen. Suatu model disebut fit bila nilai sig. $\mathrm{F}<0,05$ dan Jika Fhitung $>$ Ftabel. $F=\mathrm{F}(\mathrm{k} ; \mathrm{n}-\mathrm{k})=\mathrm{F}(4 ; 55-4)=2,56$

\begin{tabular}{|c|c|c|c|c|c|c|}
\hline \multicolumn{7}{|c|}{ ANOVAa $^{a}$} \\
\hline \multicolumn{2}{|c|}{ Model } & Sum of Squares & $\mathrm{df}$ & Mean Square & $\mathrm{F}$ & Sig. \\
\hline \multirow[t]{3}{*}{1} & Regression & 49.422 & 3 & 16.474 & 3.661 & $.018^{\mathrm{b}}$ \\
\hline & Residual & 229.487 & 51 & 4.500 & & \\
\hline & Total & 278.909 & 54 & & & \\
\hline \multicolumn{7}{|c|}{ a. Dependent Variabel: PU } \\
\hline \multicolumn{7}{|c|}{ b. Predictors: (Constant), PEOU, CR, S } \\
\hline
\end{tabular}

Tabel 4 Hasil Uji F Hipotesis 1

Sumber: Data primer diolah (2019) 
Hasil Uji H1 dapat dilihat pada tabel diatas bahwa nilai F diperoleh 3,661 dengan tingkat signifikansi 0,018. Karena tingkat signifikansi lebih keci dari 0,05 dan Fhitung > Ftabel yaitu 3,661 > 2,56 maka variabel Content Richness (CR), Security (S) dan Perceived Ease of Use (PEOU) berpengaruh secara simultan / signifikan terhadap variabel Perceived Usefullness (PU). Maka hipotesis 1 diterima.

\section{2) Pengujian Hipotesis 2}

Pengujian hipotesis 1 dilakukan untuk melihat bagaimana pengaruh variabel independen: Security terhadap variabel dependen: Perceived Easy of Use. Pengujian hipotesis ini meliputi pengujian heterokedastisitas, pengujian koefisien determinasi, analisis regresi linier sederhana serta pengujian $\mathrm{T}$.

Pada penelitian ini pegujian heteroskedastisitas menggunakan metode uji Glejser, dengan ketentuan yaitu apabila nilai signifikansi $>0,05$ sehingga tidak terjadi heteroskedastisitas, tetapi bila nilai signifikansi $<0,05$ maka kemungkinan terjadi heteroskedastisitas.

Tabel 5 Hasil Uji Heteroskedastisitas Hipotesis 2

\begin{tabular}{|c|c|c|c|c|c|c|}
\hline \multicolumn{7}{|c|}{ Coefficients $^{a}$} \\
\hline \multirow{2}{*}{\multicolumn{2}{|c|}{ Model }} & \multicolumn{2}{|c|}{ Unstandardized Coefficients } & \multirow{2}{*}{$\begin{array}{c}\begin{array}{c}\text { Standardized } \\
\text { Coefficients }\end{array} \\
\text { Beta }\end{array}$} & \multirow[t]{2}{*}{$\mathrm{t}$} & \multirow[t]{2}{*}{ Sig. } \\
\hline & & $\mathrm{B}$ & Std. Error & & & \\
\hline \multirow[t]{2}{*}{1} & (Constant) & -.898 & 2.425 & & -.370 & .713 \\
\hline & $\mathrm{S}$ & .081 & .093 & .119 & .872 & .387 \\
\hline
\end{tabular}

Sumber: Data primer diolah (2019)

Berdasarkan tabel hasil uji heteroskedastisitas Glejser di atas diperoleh hasil berikut. Variabel Security (S) memberikan nilai sig. 0, 387 > 0, 05 sehingga bisa dinyatakan variabel H2 terbebas dari masalah heteroskedastisitas.

Koefisien determinasi digunakan untuk mengukur mengenai kesesuaian regresi berganda terhadap data-datanya. Apabila tinggi nilai Adjusted $\mathrm{R}$ maka akan semakin baik pula bagi model regresi, yang berarti variabel bebas semakin mampu menjelaskan variabel terikatnya.

Tabel 6 Hasil Uji Koefisien Determinasi Hipotesis 2

\begin{tabular}{|l|c|c|c|c|}
\hline \multicolumn{5}{|c|}{ Model Summary } \\
\hline Model & $\mathrm{R}$ & R Square & Adjusted R Square & $\begin{array}{c}\text { Std. Error of the } \\
\text { Estimate }\end{array}$ \\
\hline 1 & $.745^{\mathrm{a}}$ & .555 & .547 & 1.947 \\
\hline \multicolumn{3}{|l|}{ a. Predictors: (Constant), S } & \multicolumn{3}{|c|}{} \\
\hline \multicolumn{2}{|l|}{ b. Dependent Variabel: PEOU }
\end{tabular}

Sumber: Data primer diolah (2019)

Nilai adjusted $\mathrm{R}^{2}$ 0,555 berarti daya penjelas variabel independen: Security (S) terhadap variabel dependen: Perceived Easy of Use (PEOU) adalah sebesar 56,3\%, sedangkan sisanya dijelaskan oleh faktor-faktor lain di luar model.

Analisis regresi linear berganda digunakan untuk mengetahui apakah variabel independen secara simultan berpengaruh terhadap variabel dependen. 
Tabel 7 Hasil Uji Regresi Linear Sederhana Hipotesis 2

\begin{tabular}{|c|c|c|c|c|c|c|}
\hline \multicolumn{7}{|c|}{ Coefficients $^{a}$} \\
\hline \multirow{2}{*}{\multicolumn{2}{|c|}{ Model }} & \multicolumn{2}{|c|}{ Unstandardized Coefficients } & \multirow{2}{*}{$\begin{array}{c}\begin{array}{c}\text { Standardized } \\
\text { Coefficients }\end{array} \\
\text { Beta } \\
\end{array}$} & \multirow[t]{2}{*}{$\mathrm{t}$} & \multirow[t]{2}{*}{ Sig. } \\
\hline & & $\mathrm{B}$ & Std. Error & & & \\
\hline \multirow[t]{2}{*}{1} & (Constant) & .859 & 3.155 & & .272 & .786 \\
\hline & $\mathrm{S}$ & .982 & .121 & .745 & 8.129 & .000 \\
\hline
\end{tabular}

Sumber: Data primer diolah (2019)

Berdasarkan tabel di atas dapat dituliskan ke dalam persamaan sebagai berikut:

$$
\begin{gathered}
Y=a+b X \\
Y=0,859+0,982 X
\end{gathered}
$$

Kesimpulan persamaan regresi di atas yaitu sebagai berikut:

1. Konstanta (a) sebesar 0,859, ini mengartikan bahwa nilai konstanta variabel PEOU adalah sebesar 0,859 .

2. Koefisien regresi $X$ sebesar 0,982 , menyatakan bahwa setiap penambahan $1 \%$ nilai security (S), maka nilai PEOU bertambah sebesar 0,982. Koefisien regresi tersebut bernilai positif, sehingga dapat dikatakan bahwa arah pengaruh variabel security (S) terhadap variabel Perceived Ease of Use (PEOU) adalah positif.

Uji t digunakan untuk melihat pengaruh satu variabel bebas (independen) secara parsial terhadap variabel terikat (dependen). Jika $t_{\text {hitung }}>t_{\text {tabel }}$ dan Apabila tingkat signifikansi $<0,05$ maka ada pengaruh antara variabel bebas dengan variabel terikat. Maka variabel independen secara individual berpengaruh terhadap variabel dependen.

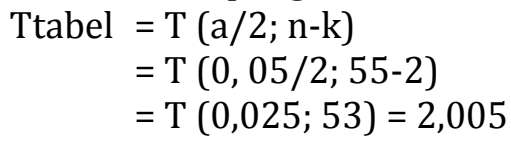

\begin{tabular}{|c|c|c|c|c|c|c|}
\hline \multicolumn{7}{|c|}{ Coefficients $^{a}$} \\
\hline \multirow{2}{*}{\multicolumn{2}{|c|}{ Model }} & \multicolumn{2}{|c|}{ Unstandardized Coefficients } & \multirow{2}{*}{$\begin{array}{c}\begin{array}{c}\text { Standardized } \\
\text { Coefficients }\end{array} \\
\text { Beta }\end{array}$} & \multirow[t]{2}{*}{$\mathrm{t}$} & \multirow[t]{2}{*}{ Sig. } \\
\hline & & B & Std. Error & & & \\
\hline \multirow[t]{2}{*}{1} & (Constant) & .859 & 3.155 & & .272 & .786 \\
\hline & $\mathrm{S}$ & .982 & .121 & .745 & 8.129 & .000 \\
\hline
\end{tabular}

Tabel 8 Hasil Uji T Hipotesis 2

Sumber: Data primer diolah (2019).

Hasil Uji T hipotesis 2 dapat dilihat pada tabel diatas bahwa nilai T untuk Security (S) diperoleh 8,129 dengan tingkat signifikansi 0,000. Karena tingkat signifikansi $<0,05$ dan Thitung > Ttabel yaitu 8,129 > 2,005 maka Security (S) berpengaruh terhadap variabel Perceived Ease of Use (PEOU). Maka hipotesis 2 diterima.

\section{3) Pengujian Hipotesis 3}

Pengujian hipotesis ini meliputi pengujian heterokedastisitas, pengujian koefisien determinasi, analisis regresi berganda serta pengujian Security (S), Perceived Easy Of Use (PEOU) dan Perceived Usefullness (PU) terhadap Consumers Intention To Use (CITU). Pengujian hipotesis ini meliputi pengujian heterokedastisitas, pengujian koefisien determinasi, analisis regresi berganda serta pengujian $\mathrm{F}$.

Pada penelitian ini pegujian heteroskedastisitas menggunakan metode uji Glejser, dengan ketentuan yaitu jika nilai signifikansi $>0,05$ maka tidak terjadi heteroskedastisitas, sebaliknya jika nilai signifikansi $<0,05$ maka terjadi heteroskedastisitas. 
Tabel 9 Hasil Uji Heteroskedastisitas Hipotesis 3

\begin{tabular}{|c|c|c|c|c|c|c|}
\hline \multicolumn{7}{|c|}{ Coefficients $^{\mathbf{a}}$} \\
\hline \multirow{2}{*}{\multicolumn{2}{|c|}{ Model }} & \multicolumn{2}{|c|}{ Unstandardized Coefficients } & \multirow{2}{*}{$\begin{array}{c}\begin{array}{c}\text { Standardized } \\
\text { Coefficients }\end{array} \\
\text { Beta } \\
\end{array}$} & \multirow[t]{2}{*}{$\mathrm{t}$} & \multirow[t]{2}{*}{ Sig. } \\
\hline & & $\mathrm{B}$ & Std. Error & & & \\
\hline \multirow[t]{4}{*}{1} & (Constant) & -.679 & 3.104 & & -.219 & .828 \\
\hline & $\mathrm{S}$ & .001 & .142 & .002 & .010 & .992 \\
\hline & PEOU & -.013 & .114 & -.025 & -.112 & .911 \\
\hline & $\mathrm{PU}$ & .101 & .098 & .156 & 1.029 & .308 \\
\hline
\end{tabular}

Sumber: Data primer diolah (2019)

Variabel Security (S), Perceived Easy of Use (PEOU) dan Perceived Usefullness (PU) memperlihatkan nilai sig. $>0,05$ sehingga dapat dinyatakan bahwa seluruh variabel H3 telah terbebas dari masalah heteroskedastisitas.

Koefisien determinasi digunakan untuk mengukur mengenai kesesuaian regresi berganda terhadap datanya. Apabila tinggi nilai Adjusted R maka akan semakin baik pula bagi model regresi, yang berarti variabel bebas semakin mampu menjelaskan variabel terikatnya.

Tabel 10 Hasil Uji Koefisien Determinasi Hipotesis 3

\begin{tabular}{|l|c|c|c|c|}
\hline \multicolumn{6}{|c|}{ Model Summary } \\
\hline Model & $\mathrm{R}$ & R Square & Adjusted R Square & $\begin{array}{c}\text { Std. Error of the } \\
\text { Estimate }\end{array}$ \\
\hline 1 & $.496^{\mathrm{a}}$ & .246 & & .202 \\
\hline \multicolumn{2}{|c|}{ a. Predictors: (Constant), PU, S, PEOU } \\
\hline \multicolumn{2}{l|}{ b. Dependent Variabel: CITU }
\end{tabular}

Sumber: Data primer diolah (2019)

Nilai adjusted $\mathrm{R}^{2}$ 0,202 berarti daya penjelas variabel independen: Security (S), Perceived Usefullness (PU), Perceived Easy of Use (PEOU) terhadap variabel dependen: Consumers Intention To Use (CITU) adalah sebesar 20,2\% sedangkan sisanya dijelaskan oleh faktor-faktor lain diluar model.

Analisis regresi linear berganda diperlukan untuk melihat apakah variabel independen secara simultan memiliki pengaruh terhadap variabel dependennya.

Tabel 11Hasil Analisis Regresi Berganda Hipotesis 3

\begin{tabular}{|c|c|c|c|c|c|c|}
\hline \multicolumn{7}{|c|}{ Coefficients $^{a}$} \\
\hline \multirow{2}{*}{\multicolumn{2}{|c|}{ Model }} & \multicolumn{2}{|c|}{ Unstandardized Coefficients } & \multirow{2}{*}{$\begin{array}{c}\begin{array}{c}\text { Standardized } \\
\text { Coefficients }\end{array} \\
\text { Beta } \\
\end{array}$} & \multirow[t]{2}{*}{$\mathrm{t}$} & \multirow[t]{2}{*}{ Sig. } \\
\hline & & $\mathrm{B}$ & Std. Error & & & \\
\hline \multirow[t]{4}{*}{1} & (Constant) & 7.982 & 4.449 & & 1.794 & .079 \\
\hline & S & .126 & .203 & .115 & .621 & .537 \\
\hline & PEOU & .026 & .163 & .032 & .162 & .872 \\
\hline & $\mathrm{PU}$ & .473 & .140 & .447 & 3.367 & .001 \\
\hline
\end{tabular}

Sumber: Data primer diolah (2019)

Berdasarkan tabel di atas dapat dituliskan ke dalam persamaan sebagai berikut:

$$
\begin{gathered}
\widehat{Y}=b 0+b 1 X 1+b 2 X 2+\cdots+b k x k \\
Y=7,982+0,126 X 1+0,026 X 2+0,473 X 3
\end{gathered}
$$

Kesimpulan persamaan regresi di atas yaitu sebagai berikut:

1. Konstanta $\left(b_{0}\right)$ sebesar 7,982 , ini mengartikan bahwa nilai konstanta variabel Consumers Intention to Use (CITU) adalah sebesar 7,982. 
2. Koefisien regresi Security (S) sebesar 0,126, menyatakan bahwa setiap penambahan 1 nilai Security (S), maka nilai Consumers Intention to Use (CITU) bertambah sebesar 0,126. Koefisien regresi tersebut bernilai positif, sehingga dapat dikatakan bahwa arah pengaruh variabel Security (S) terhadap variabel Consumers Intention to Use (CITU) adalah positif.

3. Koefisien regresi Perceived Ease of Use (PEOU) sebesar 0,026, menyatakan bahwa setiap penambahan 1 nilai Perceived Ease of Use (PEOU), maka nilai Consumers Intention to Use (CITU) bertambah sebesar 0,026. Koefisien regresi tersebut bernilai positif sehingga dapat dikatakan bahwa arah pengaruh variabel Perceived Ease of Use (PEOU) terhadap variabel Consumers Intention to Use (CITU) adalah positif.

4. Koefisien regresi Perceived Usefullness (PU) sebesar 0,473, menyatakan bahwa setiap penambahan 1 nilai Perceived Usefullness (PU), maka nilai Consumers Intention to Use (CITU) bertambah sebesar 0,473. Koefisien regresi tersebut bernilai positif, sehingga dapat dikatakan bahwa arah pengaruh variabel Perceived Usefullness (PU) terhadap variabel Consumers Intention to Use (CITU) adalah positif.

Uji model fit (uji F) digunakan untuk menguji hubungan antara satu variabel dependen dengan satu atau lebih variabel independen. Suatu model disebut fit jika nilai sig. $\mathrm{F}<0,05$ dan Jika Fhitung $>$ Ftabel.

$$
\begin{aligned}
F_{\text {tabel }}=\mathrm{F}(\mathrm{k} ; \mathrm{n}-\mathrm{k}) \\
\\
=\mathrm{F}(4 ; 55-4)=2,56
\end{aligned}
$$

\begin{tabular}{|c|c|c|c|c|c|c|}
\hline \multicolumn{7}{|c|}{ ANOVAa $^{a}$} \\
\hline \multicolumn{2}{|c|}{ Model } & Sum of Squares & $\mathrm{df}$ & Mean Square & $\mathrm{F}$ & Sig. \\
\hline \multirow[t]{3}{*}{1} & Regression & 76.617 & 3 & 25.539 & 5.545 & $.002^{\mathrm{b}}$ \\
\hline & Residual & 234.910 & 51 & 4.606 & & \\
\hline & Total & 311.527 & 54 & & & \\
\hline \multicolumn{7}{|c|}{ a. Dependent Variabel: CITU } \\
\hline \multicolumn{7}{|c|}{ b. Predictors: (Constant), PU, S, PEOU } \\
\hline
\end{tabular}

Tabel 12 Hasil Uji F Hipotesis 3

Sumber: Data primer diolah (2019)

Hasil Uji F H3 dapat dilihat pada tabel diatas bahwa nilai F diperoleh 6,437 dengan tingkat signifikansi 0,002. Karena tingkat signifikansi $<0,05$ dan $F_{\text {hitung }}>F_{\text {tabel }}$ yaitu 5,545 $>2,56$ maka variabel Security (S), Perceived Ease of Use (PEOU) dan Perceived Usefullness (PU) berpengaruh secara signifikan terhadap variabel Consumers Intention to Use (CITU). Maka hipotesis 3 diterima.

\section{Pembahasan}

Penelitian yang dilakukan di lapangan yaitu berdasarkan dari hasil akumulasi jawaban responden, didapat hasil yang menunjukkan bahwa content richness, security, perceived ease of use, perceived usefulness dan consumers intention to use pada Lazada diperoleh nilai 6.845 atau dalam persentase 69,14\%. Angka tersebut menunjukkan berada di garis kontinum kategori baik. Dengan demikian pengaruh dari content richness, security, perceived ease of use, perceived usefulness dan consumers intention to use terhadap penerimaan lazada menunjukan hasil yang sesuai dan berpotensi untuk meningkatkan penerimaan user pada aplikasi lazada.

Pembahasan pengaruh penerimaan user pada e-marketplace lazada melalui variabel Content Richness, Security dan Perceived Ease of Use terhadap Perceived Usefulness. Hasil penelitian di lapangan didapat hasil yang menyatakan bila variabel Content Richness, Security dan Perceived Ease of Use memiliki pengaruh terhadap Perceived Usefulness dengan nilai sebesar 12,9\%. Nilai tersebut menunjukkan bahwa Content Richness, Security dan Perceived Ease of Use berpengaruh secara positif terhadap Perceived Usefulness.

Pembahasan variabel Content Richness (CR), Security (S) dan Perceived Ease Of Use (PEOU) memiliki pengaruh yang positif terhadap Perceived Usefulness (PU) seperti yang ditunjukkan pada tabel 4.19. di mana nilai Perceived Usefulness (PU) akan bertambah sebesar 0,97 pada 
penambahan setiap 1 nilai Content Richness (CR), nilai Perceived Usefulness (PU) akan berkurang sebesar 1,471 pada penambahan setiap 1 nilai Security (S) dan nilai Perceived Usefulness (PU) akan bertambah sebesar 2,932 pada penambahan setiap 1 nilai Perceived Ease Of Use (PEOU), artinya bahwa kekayaan konten dan kemudahan penggunaan pada aplikasi e-marketplace Lazada berpengaruh positif terhadap kegunaan aplikasi e-marketplace Lazada itu sendiri kecuali pada keamanan yang berpengaruh negatif terhadap kegunaan e-marketplace Lazada. Hal tersebut dikarenakan bahwa aplikasi Lazada masih memiliki kekurangan pada transaksi yang dinilai masih kurang untuk menjamin kemananan saat transaksi.

Pembahasan selanjutnya terkait pengaruh penerimaan user pada e-marketplace lazada yaitu melalui variabel Security terhadap Perceived Ease of Use. Hasil penelitian di lapangan didapatkan hasil yang menunjukkan bahwa variabel Security memiliki pengaruh terhadap Perceived Ease of Use yaitu sebesar 54,7\%. Nilai tersebut membuktikan bahwa Security berpengaruh secara positif terhadap Perceived Ease of Use.

Koefisien regresi variabel Security (S) memiliki pengaruh positif terhadap Perceived Ease of Use (PEOU) seperti pada tabel 4.23. Dimana nilai Perceived Ease Of Use (PEOU) akan bertambah sebesar 8,129 pada penambahan setiap 1 nilai Security (S), artinya bahwa keamanan pada aplikasi e-marketplace Lazada berpengaruh positif terhadap kemudahan penggunaan aplikasi e-marketplace Lazada itu sendiri. Hal tersebut didukung oleh hasil penelitian yang menunjukkan bahwa Lazada dapat menjaga reputasinya.

Pembahasan terhadap pengaruh penerimaan user pada e-marketplace Lazada yaitu, melalui variabel Security, Perceived Ease of Use dan Perceived Usefulness terhadap Consumers Intention to Use. Hasil penelitian di lapangan didapatkan hasil yang menunjukkan bahwa variabel Security, Perceived Usefulness dan Perceived Ease of Use memiliki pengaruh pada Consumers Intention to Use dengan nilai sebesar 20,2\%. Besaran nilai tersebut menunjukkan bahwa Security, Perceived Usefulness dan Perceived Ease of Use berpengaruh secara positif terhadap Consumers Intention to Use.

Koefisien regresi variabel Security (S), Perceived Usefulness (PU) dan Perceived Ease Of Use (PEOU) memiliki pengaruh positif terhadap Consumers Intention to Use (CITU) seperti pada tabel 4.27. Dimana nilai Consumers Intention to Use (CITU) akan bertambah sebesar 0,621 pada penambahan setiap 1 nilai Security (S), nilai Consumers Intention to Use (CITU) akan bertambah sebesar 0,162 pada penambahan setiap 1 nilai Security (S) dan nilai Perceived Usefulness (PU) akan bertambah sebesar 3,367 pada penambahan setiap 1 nilai Perceived Ease Of Use (PEOU), artinya bahwa keamanan dan kegunaan pada aplikasi $e$-marketplace Lazada berpengaruh positif terhadap niat untuk menggunakan aplikasi e-marketplace Lazada itu sendiri. Hal tersebut didukung oleh hasi penelitian yang menunjukkan bahwa Lazada menjamin kemanan transaksi, mempermudah pekerjaan, dapat dikontrol dan pengguna Lazada mudah untuk menjadi terampil.

Hasil penelitian di atas menunjukkan bahwa para perancang bisnis e-marketpalce perlu memperhatikan hala-hal yang memberikan faktor-faktor yang pengaruh tersebut. Beberapa faktor penting diantaranya faktor kekayaan akan fitur layanan dan faktor keamanan. Karena kedua faktor ini merupakan faktor yang dapat diupayakan untuk dipenuhi dalam rangka mencapai tingkat penerimaan yang optimal. Artinya semakin banyak tawaran jasa pada suatu $e$ marketpalce makan akan semakin mudah diterima oleh para penggunanya. Begitu pula dengan faktor keamanan, bila pengguna merasakan bahwa $e$-marketpalce yang digunakan memberikan fitur ataupun proses transaksi yang aman, maka secara otomatis akan meningkatkan penerimaan akan e-marketpalce tersebut.

\section{SIMPULAN}

Berdasarkan hasil penelitian menunjukkan bahwa model yang dikembangkan telah mampu menjawab permasalahan mengenai ketiadaan model yang dapat digunakan secara spesifik untuk mengukur penerimaan pengguna terhadap produk e-marketpalce. Penelitian ini 
selain mendukung model yang dihasilkan pada penelitian Venkatesh \& Davis (1996) juga memberikan kebaruan dengan menambahkan beberapa variabel melalui dukungan penelitian Luthfihadi dan Dhewanto (2013), Pindeh et al. (2015), Lai (2016), Loanata \& Tileng (2016) dan Prakarsa (2019). Manfaat secara praktis yang didapatkan dari penelitian ini, yaitu perlu diperhatikannya faktor kekayaan fitur dan keamanan dalam pengembangan suatu $e$ marketpalce. Dengan kayanya akan fitur dan tingginya tingkat kepercayaan pengguna terhadap keamanan transaksi yang dilakukan akan mempermudah pelanggan dalam menerima produk jasa yang ditawarkan, yang dalam hal ini berbentuk e-marketpalce.

\section{DAFTAR PUSTAKA}

Davis, F.D., Bagozzi, R.P., dan Warshaw, P.R. (1989). User Acceptance of Computer Technology: A Comparison of Two Theoretical Models, Management Science, 35 (8), 982-1003.

Gefen, E. Karahanna, and D. W. Straub. 2003. Trust and TAM in shopping: An integrated model," MIS Quarterly, Igbaria M,.1994. "An Examination of the factors contributing to Micro Computer technology acceptance". Journal of Information system, Elsiever Science, USA. vol. 27, No.1, pp.51-90

Lai, V. and Li, H. 2011. "Technology acceptance model for internet banking: an invariance analysis", Information Management, Vol. 42, No.2, pp. 373- 86.

Lai, P. C. 2016. Design and Security impact on consumers' intention to use single platform Epayment. Interdisciplinary Information Sciences, 22 (1), 111-122.

Lee, J. Y. and Panteli, N. (2010). Business Strategic Conflict in Computer-mediated Communication, European Journal of Information Systems, Vol. 19, No. 2, pp. 196-208.

Loanata, T \& Tileng K.G. (2016). Pengaruh Trust dan Perceived Risk pada Intention to Use Menggunakan Technology Acceptance Model (Studi Kasus Pada Situs E-Commerce Traveloka). JUISI, Vol. 02, No. 01.

Luthfihadi, M \& Dhewanto, W. (2013). Technology Acceptance of E-commerce in Indonesia. International Journal of Engineering Innovation and Management 3 Sujana, 2001. Metode Statistik. Bandung : Tarsito.

Nielsen, J. (1994) : Usability Inspection Methods, Wiley, New York.

Pindeh, N., Suki, N. M., dan Suki, N. Mohd. (2016). User Acceptance on Mobile Apps as an Effective Medium to Learn Kadazandusun Language. Fifth International Conference On Marketing And Retailing (5TH Incomar) 2015, Procedia Economics and Finance 37 ( 2016 ) 372 - 378

Prakarsa, Graha. (2019). Analisis Faktor-Faktor yang Mempengaruhi Penggunaan E-Marketplace Shopee. SisInfo, 1(01), 1-11.

Singarimbun, M\& Sofian, E, (1995). Metode Peneltian Survey. Edisi Revisi Jakarta: LP3ES.

Sugiyono. (2012). Metode Penelitian Kuantitatif Kualitatif Dan R\&D. Bandung: Alfabeta. 
Venkatesh, V., \& Davis, F. D. (1996). A model of the antecedents of perceived ease of use: Development and test. Decision Sciences, 27(3), 451-481.

Venkatesh, Viswanath, Fred D. Davis. (2000). A Theoretical Extension of the Technology Acceptance Model: Four Longitudinal Field Studies. Management Science, 46(2), pp: 186204.

https://www.alexa.com/topsites/countries/ID, diakses 23 Juli 2019. 